\title{
Nanofactory for metabolic and chemodynamic therapy: pro-tumor lactate trapping and anti-tumor ROS transition
}

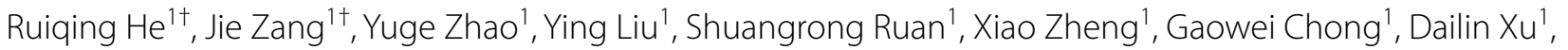
Yan Yang ${ }^{1}$, Yushan Yang ${ }^{1}$, Tingting Zhang ${ }^{1}$, Jingjing Gu${ }^{1}$, Haiqing Dong ${ }^{2^{*}}$ and Yongyong $\mathrm{Li}^{1 *}$ (D)

\begin{abstract}
Lactate plays a critical role in tumorigenesis, invasion and metastasis. Exhausting lactate in tumors holds great promise for the reversal of the immunosuppressive tumor microenvironment (TME). Herein, we report on a "lactate treatment plant" (i.e., nanofactory) that can dynamically trap pro-tumor lactate and in situ transformation into anti-tumor cytotoxic reactive oxygen species (ROS) for a synergistic chemodynamic and metabolic therapy. To this end, lactate oxidase (LOX) was nano-packaged by cationic polyethyleneimine (PEI), assisted by a necessary amount of copper ions (PLNPCu). As a reservoir of LOX, the tailored system can actively trap lactate through the cationic PEl component to promote lactate degradation by two-fold efficiency. More importantly, the byproducts of lactate degradation, hydrogen peroxide $\left(\mathrm{H}_{2} \mathrm{O}_{2}\right)$, can be transformed into anti-tumor ROS catalyzing by copper ions, mediating an immunogenic cell death (ICD). With the remission of immunosuppressive TME, ICD process effectively initiated the positive immune response in $4 \mathrm{~T} 1$ tumor model (88\% tumor inhibition). This work provides a novel strategy that rationally integrates metabolic therapy and chemodynamic therapy (CDT) for combating tumors.
\end{abstract}

Keywords: Lactate, Immunosuppressive tumor microenvironment, Immunogenic cell death, Chemodynamic therapy

\footnotetext{
*Correspondence: inano_donghq@tongji.edu.cn; yongyong_li@tongji.edu.cn

${ }^{\dagger}$ Ruiqing He and Jie Zang contributed equally to this work

${ }^{1}$ Shanghai Skin Disease Hospital, The Institute for Biomedical Engineering

\& Nano Science, School of Medicine, Tongji University, 200092 Shanghai,

China

2 Shanghai East hospital, School of Medicine, Tongji University,

200092 Shanghai, China
}

(c) The Author(s) 2021. Open Access This article is licensed under a Creative Commons Attribution 4.0 International License, which permits use, sharing, adaptation, distribution and reproduction in any medium or format, as long as you give appropriate credit to the original author(s) and the source, provide a link to the Creative Commons licence, and indicate if changes were made. The images or other third party material in this article are included in the article's Creative Commons licence, unless indicated otherwise in a credit line to the material. If material is not included in the article's Creative Commons licence and your intended use is not permitted by statutory regulation or exceeds the permitted use, you will need to obtain permission directly from the copyright holder. To view a copy of this licence, visit http://creativecommons.org/licenses/by/4.0/. The Creative Commons Public Domain Dedication waiver (http://creativeco mmons.org/publicdomain/zero/1.0/) applies to the data made available in this article, unless otherwise stated in a credit line to the data. 


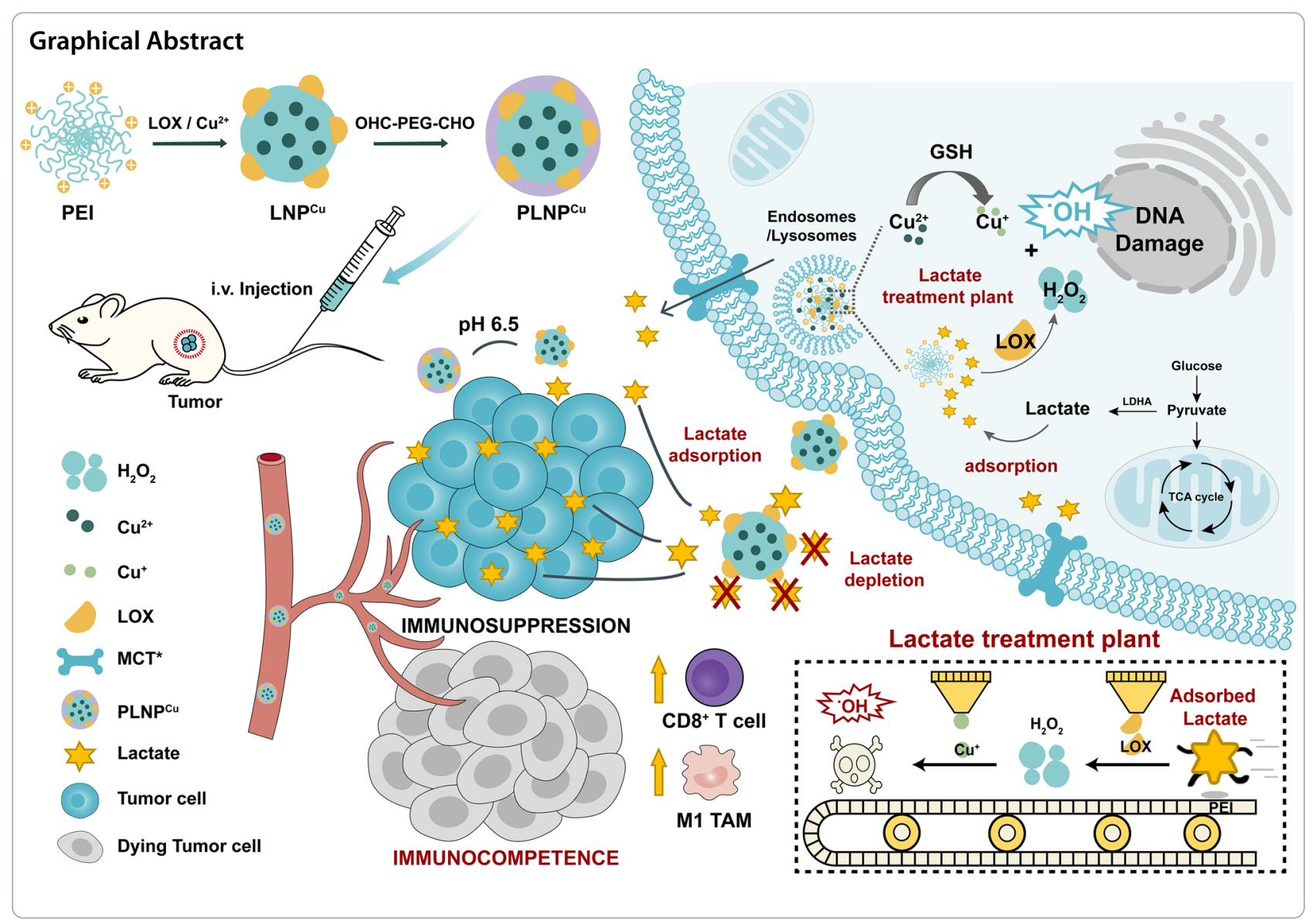

\section{Background}

The tumor microenvironment (TME) is critically important during the initiation and progression of carcinogenesis [1]. Lactate, has long been considered as the waste product of tumor aerobic glycolysis (termed as the "Warburg effect"), is now emerged as an important regulator of tumor development [2]. Increasing evidence has demonstrated that lactate acted as accomplices to assist tumor immune escape and promote tumor progression, especially through suppressing the function of multiple immune cells, such as macrophages, dendritic cells (DCs), effector T cells [3-5]. Therefore, to against cancer, several agents (glycolysis inhibitors (Dichloroacetate, DCA), MCT-inhibiting siRNA (siMCT-4) et al.) have been delivered via nanocarriers to inhibit lactate production and transportation [6, 7]. Lactate oxidase (LOX), catalyzing the oxidation of lactate to pyruvate, has also been harnessed for lactate degradation and TME regulation [8-10].

The LOX delivery based on nanocarrier represents a promising approach, as it addresses the bio-stability and side effect challenges [8]. Unfortunately, it is still facing the dilemma that the inefficiency of lactate depletion in complex TME and tumor inhibition. Most current works focused on the decomposing lactate with LOX, combined with biozym (glucose oxidase, GOx) or photodynamic therapy to enhance the anti-tumor effect, in which the introduction of additional therapeutic cargo complicated the design of nanomedicine [11, 12]. From a different perspective, we propose a strategy of "turn waste into wealth", developed to not only exhaust the lactate but also transform the hydrogen peroxide $\left(\mathrm{H}_{2} \mathrm{O}_{2}\right)$, the byproduct of lactate degradation, into cytotoxic drugs via a catalytic medicine approach.

The decomposition of lactate with LOX produces $\mathrm{H}_{2} \mathrm{O}_{2}$, [13] which can be harnessed to realize Fenton reaction with Fenton agents (e.g., $\mathrm{Cu}^{2+}, \mathrm{Fe}^{3+} / \mathrm{Fe}^{2+}$ ) to produce more cytotoxic hydroxyl radicals $(\cdot \mathrm{OH})$ for tumor killing, namely chemodynamic therapy (CDT) [14]. Meanwhile, excess reactive oxygen species (ROS) induce immunogenic cancer cell death (ICD), and promote the secretion of various pro-inflammatory cytokines from immune cells, (e.g., interferon- $\gamma$ (IFN- $\gamma$ ), interleukin-6 (IL-6), tumor necrosis factor (TNF)), thereby enhancing the inflammatory response in tumor sites for further immune activation [15]. Since $\mathrm{Fe}^{2+}$-catalyzed Fenton 


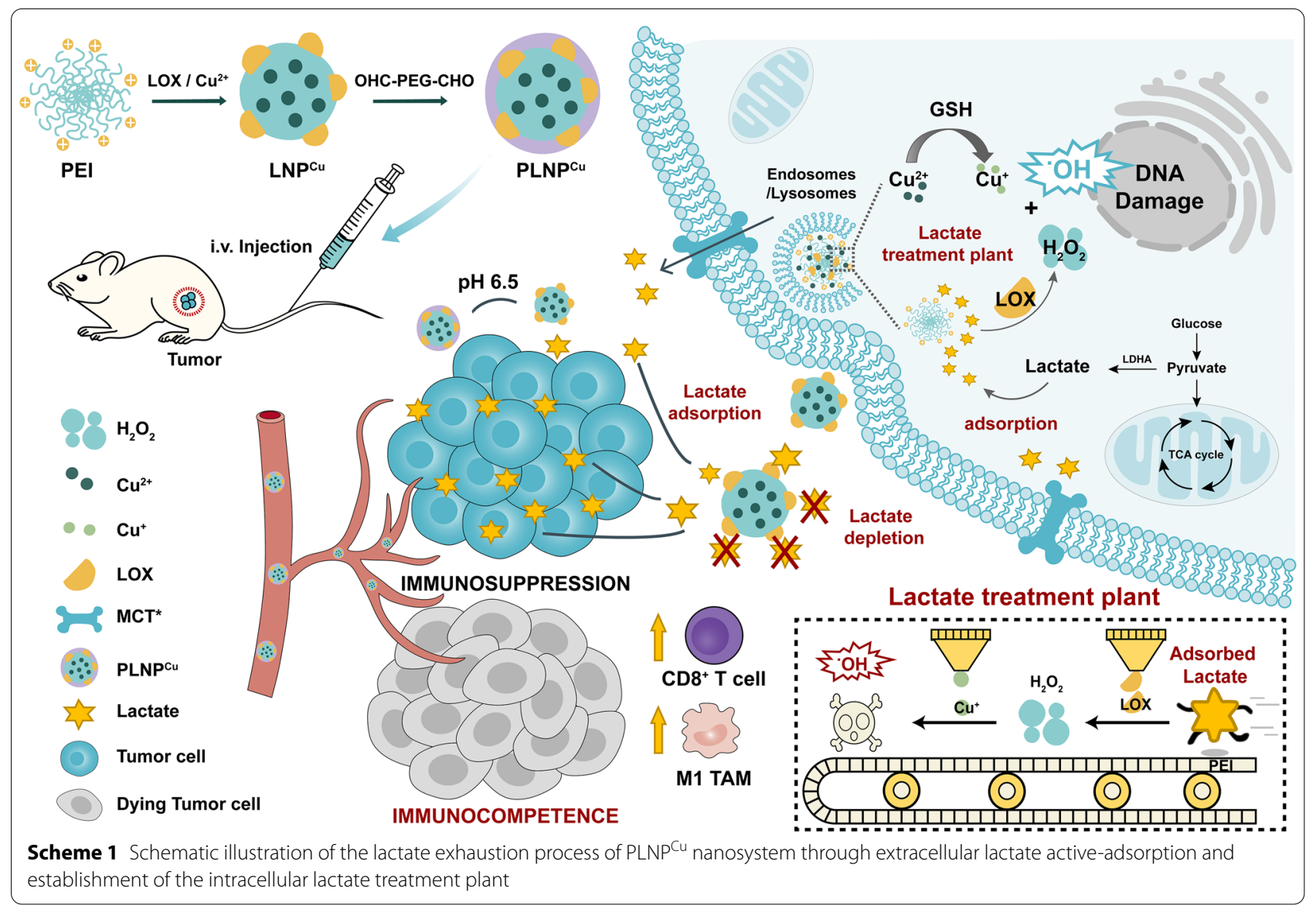

reaction efficiency was restrained by strongly acidic conditions ( $\mathrm{pH} 2-4) \cdot \mathrm{Cu}^{2+}$, possessing a higher reaction rate of $\sim 160$-fold of $\mathrm{Fe}^{2+}$ in the weakly acidic and neutral media, could be a better choice [14, 16-18].

Accordingly, herein, we developed the "lactate treatment plant" (i.e., nanofactory) that can dynamically trap pro-tumor lactate and in situ transformation into antitumor cytotoxic ROS for a synergistic chemodynamic and metabolic therapy. As shown in Scheme 1, cationic polyethyleneimine (PEI), possessing robust acid trapping ability, was chosen as the carrier for loading LOX and $\mathrm{Cu}^{2+}$ through electrostatic interaction and coordination, named as $\mathrm{LNP}^{\mathrm{Cu}}$. The $\mathrm{pH}$-responsive detachable polyethylene glycol (OHC-PEG-CHO) shell endows LNP $\mathrm{Cu}$ with stability and biocompatibility (PLNPCu ). Upon acidtriggered shell shedding, lactate gathered surrounding the "nanofactory" through the "active trapping" of the exposed primary amine on PEI. Then the LOX contained in "nanofactory" facilitated the lactate catalysis to generate $\mathrm{H}_{2} \mathrm{O}_{2}$ which was continuously transformed into toxic . OH through the Fenton-like reaction. In this fashion, the lactate depletion by the cascade catalysis process reversed lactate-induced suppression of immune cells function in TME, and more importantly, its product of ROS subsequently induced ICD and anti-tumor immunity. Therapeutically, the "lactate treatment plant" significantly inhibited the growth of $4 \mathrm{~T} 1$ breast cancer.

\section{Results and discussion}

\section{Synthesis and characterization of PLNPCu}

The $\mathrm{LNP}^{\mathrm{Cu}}$ can quickly assemble by mixing polyethyleneimine (PEI), copper ions $\left(\mathrm{Cu}^{2+}\right)$ and lactate oxidase (LOX) under gentle stirring at room temperature (see supporting information for the detailed description of the preparation). The driving force for the assembly was mainly electrostatic interaction and coordination among $\mathrm{Cu}^{2+}$, PEI and LOX. The obtained $\mathrm{LNP}^{\mathrm{Cu}}$ have the hydrodynamic size of $115 \pm 5.0 \mathrm{~nm}$ with a narrow polydispersity index (PDI) of 0.14 by dynamic light scattering (DLS) (Additional file 1: Fig. S1d).

To improve the circulation stability and biocompatibility, the surface of the $\mathrm{LNP}^{\mathrm{Cu}}$ was shielded with polyethylene glycol derivates with the double end group of aldehyde (OHC-PEG-CHO) through pH-responsive Schiff base (named as PLNPCu). As shown in the ${ }^{1} \mathrm{H}$ NMR spectra, the disappearance (at $\mathrm{pH}$ 7.4) and reappearance 
(at $\mathrm{pH}$ 6.5) of the hydrogen peak for aldehyde groups in the dotted area suggested that the acid-responsive labiality of Schiff bases formed by PEI with aldehyde groups of OHC-PEG-CHO (Additional file 1: Fig. S4). PLNPCu showed well-dispersed uniform spherical structures (Fig. 1a) with a visible PEG shell at $\mathrm{pH} 7.4$ by transmission electron microscopy (TEM) (Fig. 1b). The hydrodynamic size of PLNPCu was $218 \pm 3.0 \mathrm{~nm}$ (PDI 0.06), which was consistent well with the TEM results (Fig. 1d). Notably, PLNPCu exhibited the compression of zeta potential comparing with $\mathrm{LNP}^{\mathrm{Cu}}(27.07 \mathrm{mV}$ vs. $18.07 \mathrm{mV}$ ) (Fig. 1e).
However, the rebound of zeta potential from $18.07 \mathrm{mV}$ to $27.50 \mathrm{mV}$ (Fig. 1e) occurred at the weakly acidic condition (at $\mathrm{pH} 6.5$, the $\mathrm{pH}$ of most solid tumor environment) [19], indicating PEG shell could be shed from the surface of PLNPCu to exposure of the positive charged amino. More intuitively, the shellless PLNP ${ }^{\mathrm{Cu}}$ upon incubated in $\mathrm{H}_{2} \mathrm{O}$ at $\mathrm{pH} 6.5$ could be viewed in TEM images, as was shown in Fig. 1c and Additional file 1: Fig. S1a.

Further, the size of PLNP ${ }^{\mathrm{Cu}}$ was stable in neutral PBS solution within 48-hour monitoring (Fig. 1f) accompanied by a low release of LOX $(26.25 \% \pm 2.676)$ (Fig. $1 \mathrm{~h})$, a

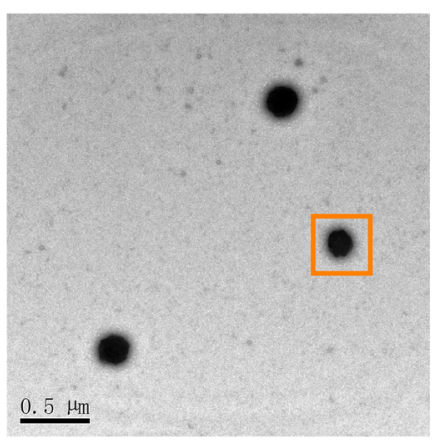

d

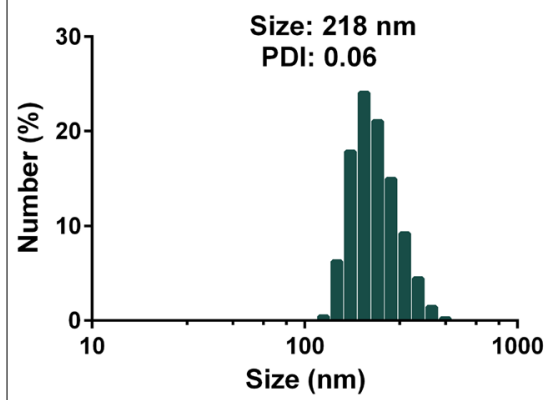

g

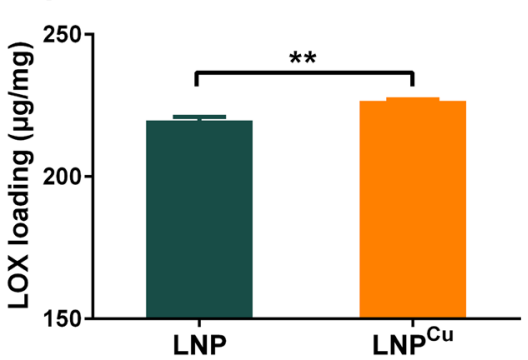

e

h b
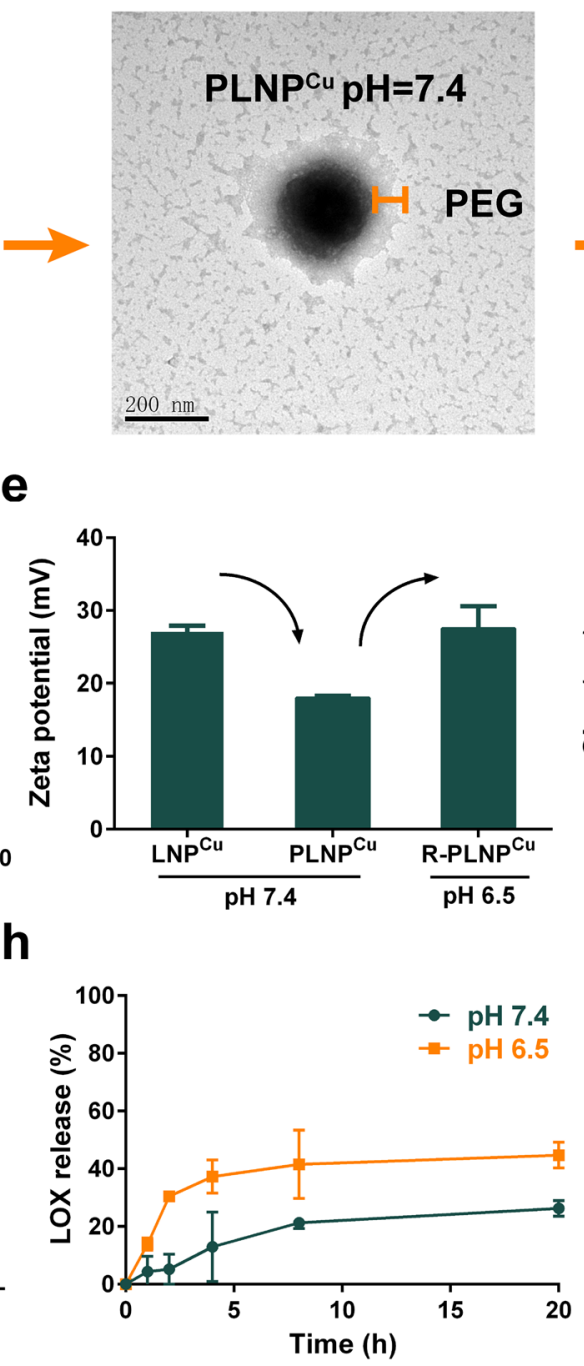

C

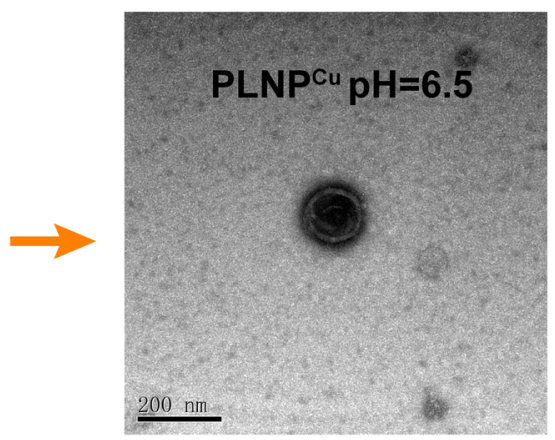

f

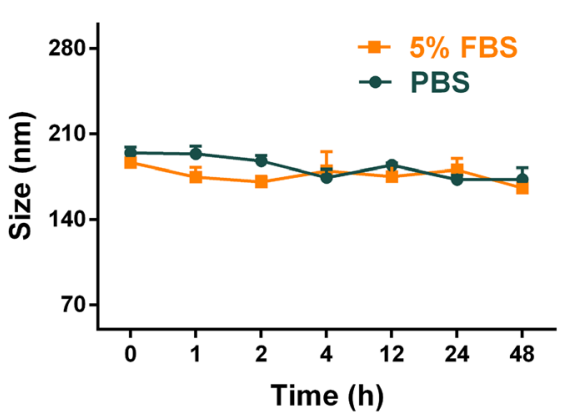

I

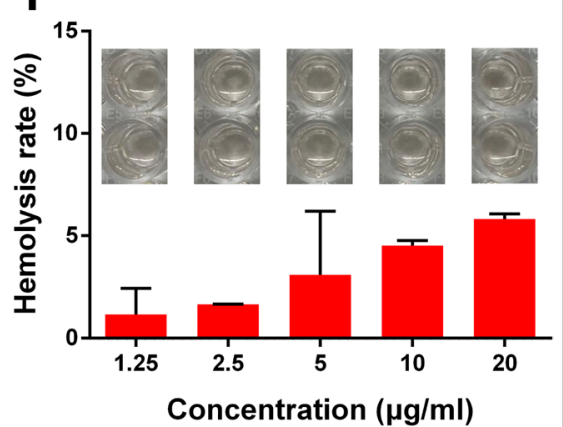

Fig. 1 Characterization of PLNPCu a, b TEM images of PLNPCu at pH 7.4. $\mathbf{c}$ TEM images of PLNPCu at pH 6.5. $\mathbf{d}$ DLS of PLNPCu at pH 7.4. e The $\mathrm{pH}$-triggered charge rebound behavior of PLNPCu $(n=3)$. $\mathbf{f}$ Maintenance of size stability of PLNPCu in PBS and PBS with $5 \% \mathrm{FBS}($ at $\mathrm{pH} 7.4)(\mathrm{n}=3)$. $\mathbf{g}$ LOX loading capacities on LNP and LNPCu respectively $(n=3)$. $\mathbf{h}$ Cumulative release of LOX from PLNPCu in PBS at pH 7.4 and pH $6.5(n=3)$. $\mathbf{i}$ Hemolysis rate of PLNPCu at different PEI concentrations $(n=3)$. Results were expressed as mean \pm SD. The significant difference was calculated via two-tailed t-test analysis (g). (NS represented not significant, ${ }^{*} p<0.05,{ }^{* *} p<0.01,{ }^{* * *} p<0.001$ ) 


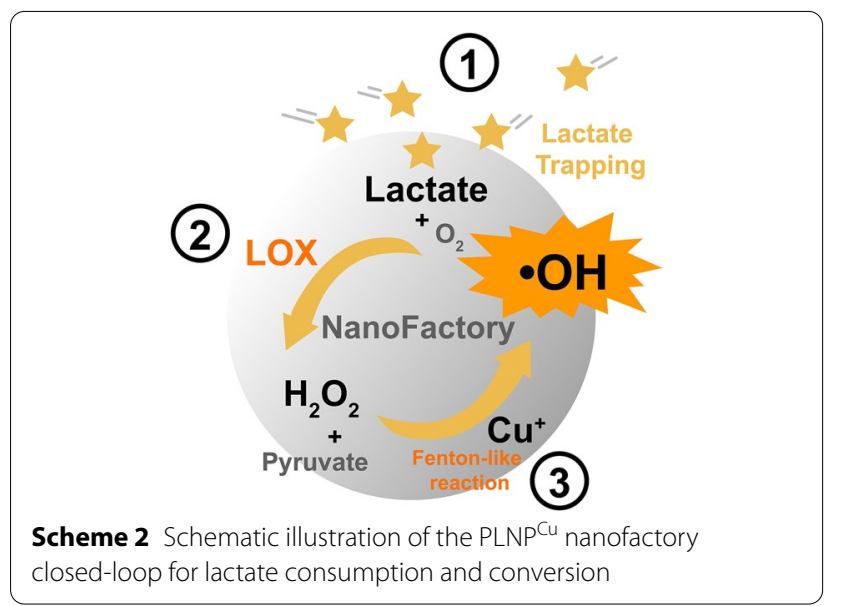

the content of LOX was quantified with the Bradford Protein Assay Kit according to the standard curve (Additional file 1: Fig. S3), while the moderate LOX release behavior was found at pH $6.5(44.74 \% \pm 4.456)$ (Fig. 1h). The morphology of the PLNPCu at $\mathrm{pH} 5.5$ was also explored (Additional file 1: Fig. S1b), which suggested the potential for effective function exertion in the intracellular milieu. Apparently, the introduction of copper ion (with entrapment efficiency of $\sim 81.58 \%$ determined by inductively coupled plasma mass spectrometry (ICPMS)) may facilitate LOX loading in $\mathrm{LNP}^{\mathrm{Cu}}$ compared with the LNP with a smaller size (Additional file 1: Fig. S1c) which could be attributed to the coordination of metal ions (LOX \%: $226.6 \pm 0.518$ vs. $219.7 \pm 1.237 \mu \mathrm{g}$ $\mathrm{mg}^{-1}$ ) (Fig. 1g). In addition, hemolytic toxicity tests showed the biosafety of PLNPCu through intravenous administration (Fig. 1i).

\section{Evaluation of PLNPCu as lactate treatment plant in vitro} $\mathrm{PLNP}^{\mathrm{Cu}}$, referred to as extra/intracellular lactate treatment plant, for lactate consumption and tumor cell inhibition were investigated. As shown in Scheme 2, the lactate treatment plant elicited a chain of the response of processing lactate to antipersonnel reactive oxygen species (ROS) capitalized on the tumor cell physiology and tumor microenvironments (TME), such as acidic microenvironment and the relatively high GSH/GSSG ratios $[20,21]$. Briefly, the entire process can be categorized into three stages. First, the local high lactate concentration is formed by PEI trapping; second, lactate reacts with oxygen to produce hydrogen peroxide $\left(\mathrm{H}_{2} \mathrm{O}_{2}\right)$ under the catalysis of LOX; finally, the Fenton-like reaction between copper ions and enzymatic product $\left(\mathrm{H}_{2} \mathrm{O}_{2}\right)$ from the second step produces a large number of hydroxyl radicals $(\cdot \mathrm{OH})$. The verification for the above three stages was investigated as follows.
Inspired by the cationic polymer of PEI with a large number of primary amino groups, we speculated that these positive charged groups could electrostatically interact with lactate and attract to the PLNP ${ }^{\mathrm{Cu}}$ nanosystem. We thus carefully studied the adsorption behavior of PLNPCu. Considering the LOX may influence the determination of lactate absorption of PLNP ${ }^{\mathrm{Cu}}$, bovine serum albumin (BSA) was used to replace LOX, regarding their high similarity in structure and properties (isoelectric point, pI 4.7 vs. 4.6 , molecular weight $\approx 66 \mathrm{kDa}$ vs. $80 \mathrm{kDa}$ ) except for catalysis for lactate, and was fabricated according to the synthetic procedure of $\mathrm{LNP}^{\mathrm{Cu}}$ and $\mathrm{PLNP}^{\mathrm{Cu}}$ (named as $\mathrm{BNP}^{\mathrm{Cu}}$ and $\mathrm{PBNP}^{\mathrm{Cu}}$, respectively). Both zeta potential and hydrodynamic size of $\mathrm{BNP}^{\mathrm{Cu}}$ and $\mathrm{PBNP}^{\mathrm{Cu}}$ were consistent with PLNPCu (Additional file 1: Fig. S2b). Subsequently, the PEI, BNPCu, and PBNPCu at different $\mathrm{pH}$ with an equimolar amount of PEI were mixed with NaL respectively and shaken overnight at 37 ${ }^{\circ} \mathrm{C}$. Followed by fully dialyzed for $4 \mathrm{~h}$ and the dialysate of different groups was collected for lactate analysis. The high lactate adsorption rate of $\mathrm{BNP}^{\mathrm{Cu}}(19.54 \% \pm 0.559)$ and $\mathrm{PBNP}^{\mathrm{Cu}}(\mathrm{pH}=6.5)(13.56 \% \pm 0.0284)$ were consistent with that of PEI solution $(17.24 \% \pm 1.07)$, while the $\mathrm{PBNP}^{\mathrm{Cu}}(4.369 \% \pm 0.0583)$ and control groups $(5.804 \%$ $\pm 0.429)$ at $\mathrm{pH} 7.4$ showed much lower levels of lactate adsorption compared to above three groups (Fig. 2a). The above results verified that the exposure of PEI on the $\mathrm{PLNP}^{\mathrm{Cu}}$ nanosystem played an important role in lactate recruitment, and the detachable PEG shell contributed to the shielding effect in the neutral milieu.

To evaluate the lactate consumption-ability of the nanoparticles, $\mathrm{LNP}^{\mathrm{Cu}}$ and $\mathrm{BNP}^{\mathrm{Cu}}$ were added into $\mathrm{NaL}$ solution respectively. The concentration of lactate in the mixed solution containing $\mathrm{LNP}^{\mathrm{Cu}}$ decreased with time compared to $\mathrm{BNP}^{\mathrm{Cu}}$ (Fig. 2b), which demonstrated the maintenance of the catalytic activity of LOX. We further studied the degradation of lactate over a short time frame (10 or $20 \mathrm{~min}$ ) at different $\mathrm{pH}$. Surprisingly, after being incubated for $20 \mathrm{~min}$, the lactate degradation rate of $\mathrm{LNP}^{\mathrm{Cu}}$ was almost four-fold higher than the free LOX group at $\mathrm{pH} 7.4(26.16 \% \pm 0.102$ vs. $6.727 \% \pm 0.0298)$, even reaching the $\sim 43$ times level in $10 \mathrm{~min}$ of reaction $(18.71 \%$ vs. $0.429 \%)$. And $\mathrm{LNP}^{\mathrm{Cu}}$ exhibited an excellent catalytic activity even at $\mathrm{pH} 5.5(7.977 \% \pm 0.122)$ (Fig. 2c). Immediately after, the degradation rate of lactate following $2 \mathrm{~h}$ exposure to $\mathrm{LNP}^{\mathrm{Cu}}$ was studied. The result showed that the catalytic activity of $\mathrm{LNPCu}^{\mathrm{Cu}}$ at different $\mathrm{pH}$ values $(\mathrm{pH} 7.4,6.5$, and 5.5) was significantly higher than the respective values of free LOX groups (Fig. 2d). It was speculated that the discrepancy was likely because of the adsorption effect of PEI in favor of shortening the "lactate-hunting" for LOX, and local high concentration of lactate was more favorable for the 


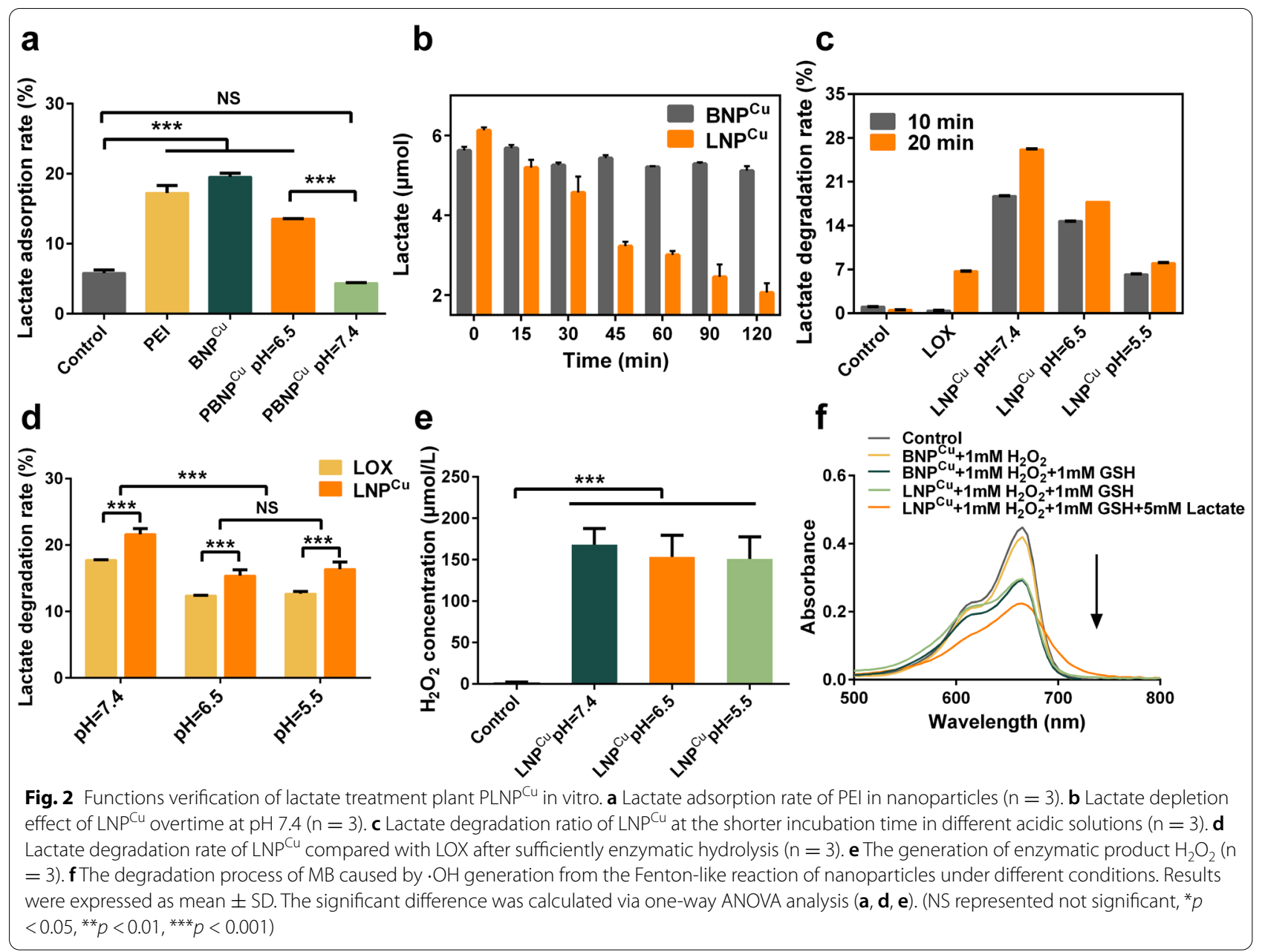

performance of enzymatic hydrolysis reaction. The above results indicated that the lactate adsorption effect of PEI contributed to the enhance of lactate degradation at different $\mathrm{pH}$.

Based on the above exciting results, the third process in the lactate treatment plant that $\cdot \mathrm{OH}$ production by reacting $\mathrm{H}_{2} \mathrm{O}_{2}$ with $\mathrm{Cu}^{+}$was explored. The concentration of $\mathrm{H}_{2} \mathrm{O}_{2}$ was quantified via the Hydrogen Peroxide Assay Kit according to the standard curve (Additional file 1: Fig. S5). The LOX solution was mixed with $\mathrm{NaL}$ solution and thoroughly reacted for $1 \mathrm{~h}$ at $37^{\circ} \mathrm{C}$ and then the $\mathrm{H}_{2} \mathrm{O}_{2}$ concentration of the supernatant was detected. As shown in Additional file 1: Fig. S6, $\mathrm{H}_{2} \mathrm{O}_{2}$ was barely detected without $\mathrm{NaL}$, which has excluded the effect of residual $\mathrm{H}_{2} \mathrm{O}_{2}$ background. And the generation of $\mathrm{H}_{2} \mathrm{O}_{2}$ increased along with increasing $\mathrm{NaL}$ concentration. This directly demonstrated the LOX catalyzed reaction of lactate $+\mathrm{O}_{2}-$ pyruvate $+\mathrm{H}_{2} \mathrm{O}_{2}$. After that, the generation of $\mathrm{H}_{2} \mathrm{O}_{2}$ produced by $\mathrm{LNP}^{\mathrm{Cu}}$ at different $\mathrm{pH}$ conditions ( $\mathrm{pH} 7.4,6.5$ and 5.5) compared with free LOX solution was recorded. The $\mathrm{H}_{2} \mathrm{O}_{2}$ concentration was comparable in both groups which demonstrated carrier and $\mathrm{pH}$ change did not show interference in this process (Fig. 2e and Additional file 1: Fig. S7). The methylene blue (MB) degradation was used to validate the Fentonlike reaction occurrence. We simulated the process of intracellular high levels of GSH $(5-10 \mathrm{mM})$ induced the conversion of cupric ions $\left(\mathrm{Cu}^{2+}\right)$ to cuprous form $\left(\mathrm{Cu}^{+}\right)$ [20]. Briefly, GSH was added into the supernatant of $\mathrm{BNP}^{\mathrm{Cu}}$ and $\mathrm{LNP}^{\mathrm{Cu}}$ solution respectively for $\mathrm{Cu}^{+}$generation, then the $\mathrm{H}_{2} \mathrm{O}_{2}$ and $\mathrm{NaL}$ solution were added in turn. The appropriate feeding amount of $\mathrm{H}_{2} \mathrm{O}_{2}, \mathrm{GSH}$ and $\mathrm{NaL}$ was identified from references [22, 23]. The reduction in absorbance of MB showed that additional lactate evoked a huge elevation of toxic $\cdot \mathrm{OH}$ in the orange group (with lactate addition) compared to light green groups (without lactate addition) (Fig. 2f). It was proven that the $\mathrm{Cu}^{+}$ resulted from GSH reduction can react with $\mathrm{H}_{2} \mathrm{O}_{2}$ to produce $\cdot \mathrm{OH}$, since the $\mathrm{OH}$-induced $\mathrm{MB}$ indicator degradation caused the change in absorbance [22]. All the results supported a well-functioning lactate treatment plant in vitro. 
Intracellular behaviors of PLNPCu

As breast tumors exhibit immunosuppression and Warburg phenotype (with strong aerobic glycolysis induced lactate buildup), 4T1 cell line was chosen for further study [24]. We first examined the cytotoxicity of PLNPCu on $4 \mathrm{~T} 1$ cells. As shown in Fig. $3 \mathrm{a}, \mathrm{PLNP}^{\mathrm{Cu}}$ at both low and high concentrations induced high cytotoxicity compared with the free LOX group. The higher cell viability upon treatment with $\mathrm{PLNP} \mathrm{Cu}^{\mathrm{Cu}}(\mathrm{pH}=7.4)$ suggested the protective role of the PEG shell at low concentrations. Once the acid-sensitive reaction was triggered, $\mathrm{LNP}^{\mathrm{Cu}}$ and $\mathrm{PLNP}^{\mathrm{Cu}}(\mathrm{pH}=6.5)$ showed similar high efficacy for killing 4T1 cells (Additional file 1: Fig. S8). Besides, $\mathrm{PBNP}^{\mathrm{Cu}}$ exhibited relatively low cytotoxicity even at high concentrations $\left(2.5 \mu \mathrm{g} \mathrm{mL}^{-1}\right)$ (Additional file 1: Fig. S9), which demonstrated that the establishment of an intracellular

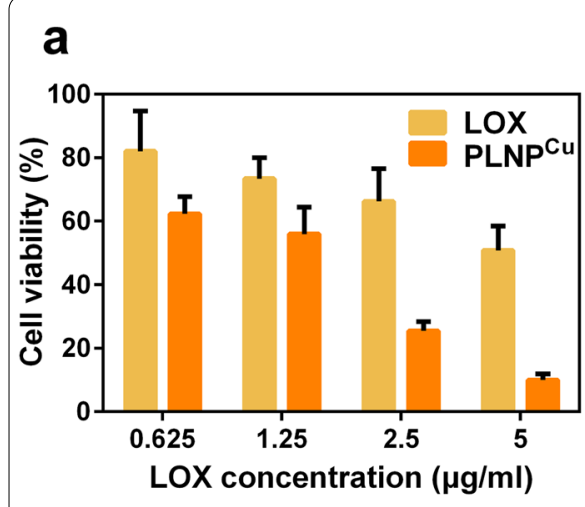

b
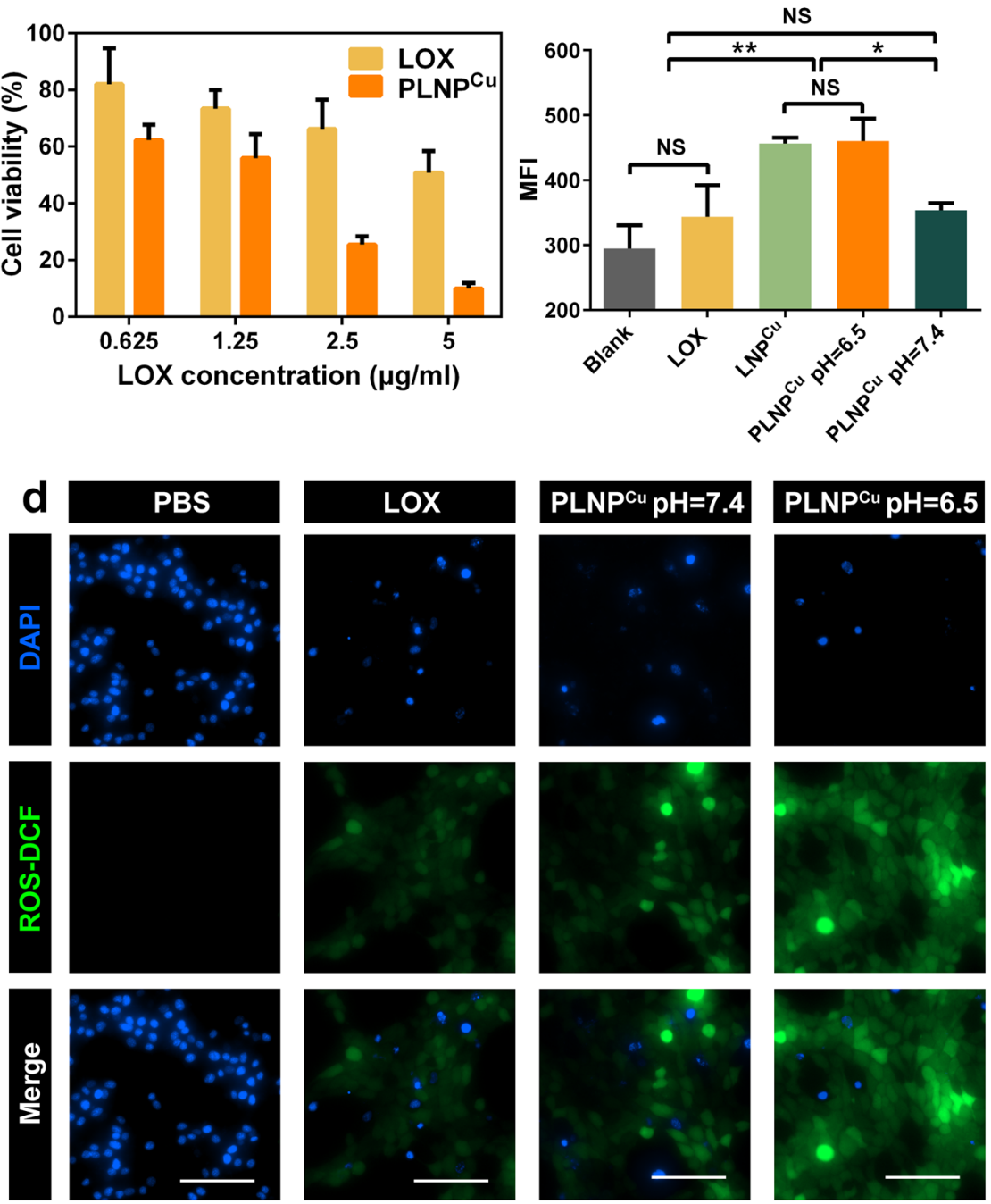

C
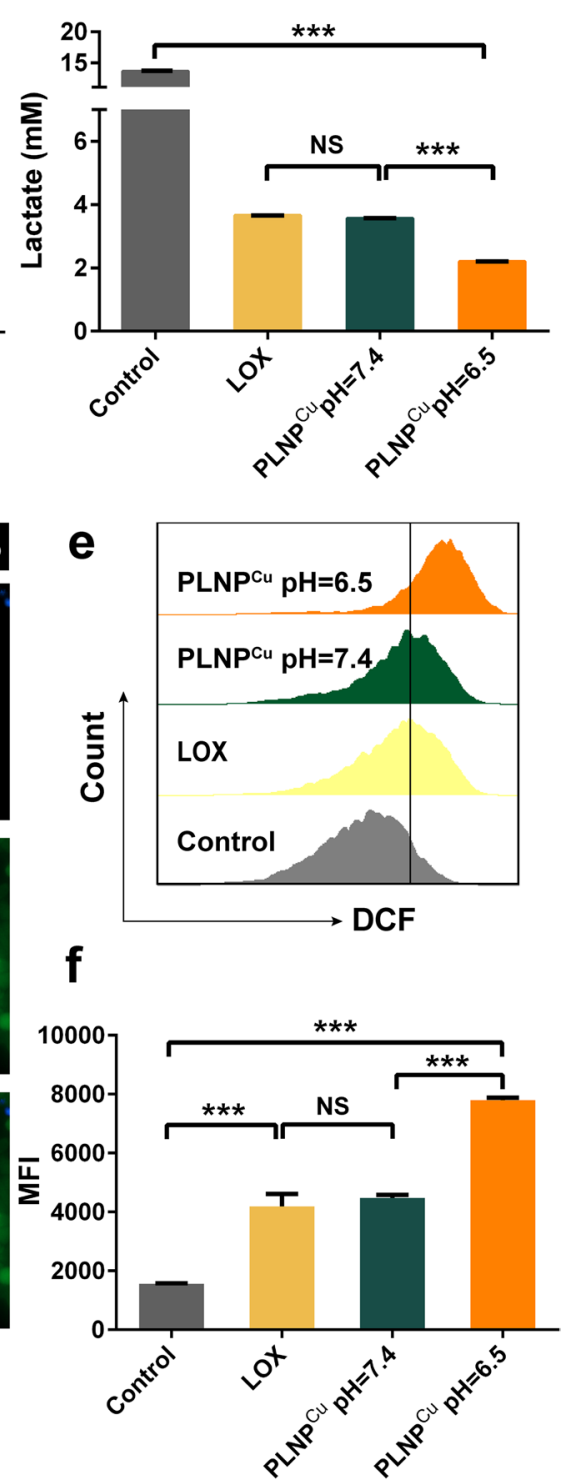

Fig. 3 Intracellular behaviors of PLNPCu a The cytotoxicity of PLNPCu and LOX against 4T1 cells $(n=5)$. b The flow cytometry analysis of cellular uptake of different agents (LOX@FITC, LNPCu@FITC, PLNPCu@FITC pH=7.4 and PLNPCu@FITC pH=6.5) after 3 h of incubation with 4T1 cells. (n= 3) c The lactate consumption analysis in 4T1 cell supernatant after treatment with PLNPCu. $(n=3) \mathbf{d}$ Fluorescent microscopy image of intracellular ROS generation. Scale bars, $100 \mu \mathrm{m}$. e, f The flow cytometry analysis of ROS generation after treatment with PBS, LOX, PLNPCu pH = 6.5 and PLNPCu $\mathrm{pH}=7.4$. Results were expressed as mean \pm SD. The significant difference was calculated via one-way ANOVA analysis (b, $\mathbf{c}, \mathbf{f}$ ). (NS represented not significant, $\left.{ }^{*} p<0.05,{ }^{* *} p<0.01,{ }^{* * *} p<0.001\right)$ 
lactate treatment plant played a critical role in the efficient killing of tumor cells. Then, the cellular uptake of $\mathrm{LNP}^{\mathrm{Cu}}$ was examined by flow cytometry. $4 \mathrm{~h}$ of incubation with LNP ${ }^{\mathrm{Cu}} @$ FITC appeared to reach the saturation of cellular uptake for comparable fluorescence intensity as that of $3 \mathrm{~h}$, indicating that the optimal incubation time Additional file 1: Fig. S10. Particularly, both $\mathrm{LNP}^{\mathrm{Cu}}$ and $\operatorname{PLNP}^{\mathrm{Cu}}(\mathrm{pH}=6.5)$ had similar high cellular uptakes in 4T1 cells compared to free LOX and PEG-shielded nanoparticles ( $\mathrm{PLNP}{ }^{\mathrm{Cu}} \mathrm{pH}=7.4$ ) (Fig. 3b). Taken together, the superior cellular uptake of detached-shell PLNPCu and establishment of the intracellular lactate treatment plant account for the toxicity of PLNPCu to 4T1 cells.

Subsequently, the lactate consumption effect of $\mathrm{PLNP}^{\mathrm{Cu}}$ was evaluated at the cellular level. Notably, the $\operatorname{PLNP}^{\mathrm{Cu}}(\mathrm{pH}=6.5)$ group showed the lowest levels of lactate among the experimental groups (Fig. 3c), suggesting that the lactate adsorption caused by PEI exposure on the surface of PLNPCu promoted the lactate consumption process, which was consistent with the functions verification results in vitro. It also showed the potent inhibition of intra/extracellular lactate. The $\cdot \mathrm{OH}$ generation induced by $\mathrm{PLNP}^{\mathrm{Cu}}$ was investigated using $2^{\prime}, 7^{\prime}$-dichlorofluorescein diacetate (DCFH-DA) as a ROS indicator. From the fluorescent microscopy images, 4T1 cells treated with free LOX and PBS showed negligible fluorescence. And the faint fluorescence in PLNPCu $(\mathrm{pH}=7.4)$ group might be induced by the endocytosis of a small number of PLNPCu (Fig. 3d). In contrast, stronger green fluorescence was observed in $\mathrm{PLNP}^{\mathrm{Cu}}(\mathrm{pH}=6.5)$ treated cancer cells (Fig. 3d), indicating the relatively high $\cdot \mathrm{OH}$ levels rather than $\mathrm{H}_{2} \mathrm{O}_{2}$. Since the mean fluorescence intensity (MFI) in PLNP $(\mathrm{pH}=6.5)$ (the detailed information of PLNP were shown in Additional file 1: Fig. S2a) treated 4T1 cells was insufficient as well (Additional file 1: Fig. S11). Consistent with fluorescent microscopy images, flow cytometry results also demonstrated the critical role in triggering $\cdot \mathrm{OH}$ formation of copper ions in $\mathrm{PLNP}^{\mathrm{Cu}}$ (Fig. 3e, f). Overall, $\mathrm{PLNP}^{\mathrm{Cu}}$ showed the specific function to convert the lactate into the toxic $\cdot \mathrm{OH}$ product through the intracellular Fenton-like reaction, which indicated the successful construction of the intracellular lactate treatment plant.

\section{Immunomodulatory effects on macrophages and ICD induction effects of PLNPCu in vitro}

. OH, a highly toxic type of ROS, causes oxidative damages to lipids, proteins, and DNA which in turn results in the apoptosis of tumor cells [25]. The apoptosis and necrosis induced by PLNPCu of $4 \mathrm{~T} 1$ cells were evaluated by annexin V-FITC and propidium iodide (PI) staining assay. The flow cytometry results showed that the percentage of late apoptosis and necrosis in the PLNP ${ }^{\mathrm{Cu}}$
$(\mathrm{pH}=6.5)$ group $(56.15 \%)$ was nearly 2 -fold than other groups (Control $\sim 35.32 \%$, LOX $\sim 34.63 \%$, PLNPCu $\mathrm{pH}=7.4-36.16 \%$ ), demonstrating the build of the lactate treatment plant in tumor cells and the excellent chemodynamic therapy (CDT) performance (Fig. 4a, b).

We further investigated the immunogenic cell death (ICD) level of 4T1 cells induced by the lactate treatment plant. As three representative markers of ICD, the expression of calreticulin (CRT), the efflux of high-mobility group box 1 (HMGB1) from the tumor cell nucleus, and the secretion of adenosine triphosphate (ATP) were evaluated, which were critical for activating the adaptive immune response and anti-tumor $\mathrm{T}$ cell immunity [26]. As the results were shown in Fig. 4c and d, the CRT expression on tumor surface after being treated with PLNP $^{\mathrm{Cu}}(\mathrm{pH}=6.5)$ increased to $68.57 \%$, which was considerably 1.29-fold higher than that in the control group. However, the positive rate of CRT in the LOX group $(\sim 55.40 \%)$ was insignificantly increased compared with controls, indicating that intracellular $\mathrm{H}_{2} \mathrm{O}_{2}$ was insufficient to trigger ICD. A similar result was reconfirmed in the immunofluorescence (Fig. 4e). Additionally, HMGB1 is normally localized in the cell nucleus, while the weak green fluorescence at cell nuclei in PLNP ${ }^{\mathrm{Cu}}(\mathrm{pH}=6.5)$, demonstrating the large quantities of HMGB1 extracellular released compared with the PBS treatment cells (Fig. 4f). For ATP secretion, PLNP ${ }^{\mathrm{Cu}}$ treatment resulted in higher ATP in the cellular supernatant (Fig. 4g). Notably, it was Fenton-like chemistry driven by cuprous ions that were the main reason for ICD, based on the results of the lower ATP release in PLNP $(\mathrm{pH}=6.5)$ group compared with $\mathrm{PLNP}^{\mathrm{Cu}}(\mathrm{pH}=6.5)$ (Additional file 1: Fig. S12). The evidence above suggested that the intracellular lactate treatment plant activated by $\mathrm{PLNP}^{\mathrm{Cu}}$ converted lactate into anti-tumor $\cdot \mathrm{OH}$, thereby producing considerable effects on ICD induction in tumor cells, paving the way for anti-tumor immune responses.

As one of the components of innate immunity in TME, macrophages are the major immune component of leukocyte infiltration in the tumor [27]. Unfortunately, lactate efflux associated with lactate accumulation and acid microenvironment suppressed its proliferation and inhibited macrophage M1 polarization [3, 28]. The markers (CD80, CD206) of RAW 264.7 macrophages were analyzed by flow cytometric analysis to determine the polarization after stimulating by the $\mathrm{PLNP}^{\mathrm{Cu}} .1 \mu \mathrm{g}$ $\mathrm{mL}^{-1}$ of LOX was chosen as the safe dose concentration according to the results of the cytotoxicity experiments (Additional file 1: Fig. S13). The results showed that expression of CD80 (M1 macrophages marker) on the cell surface significantly upregulated with the time increase of PLNPCu stimulation. Especially, it was up to $9.22 \%$ after $24 \mathrm{~h}$ of stimulation, which was 3 -fold higher 


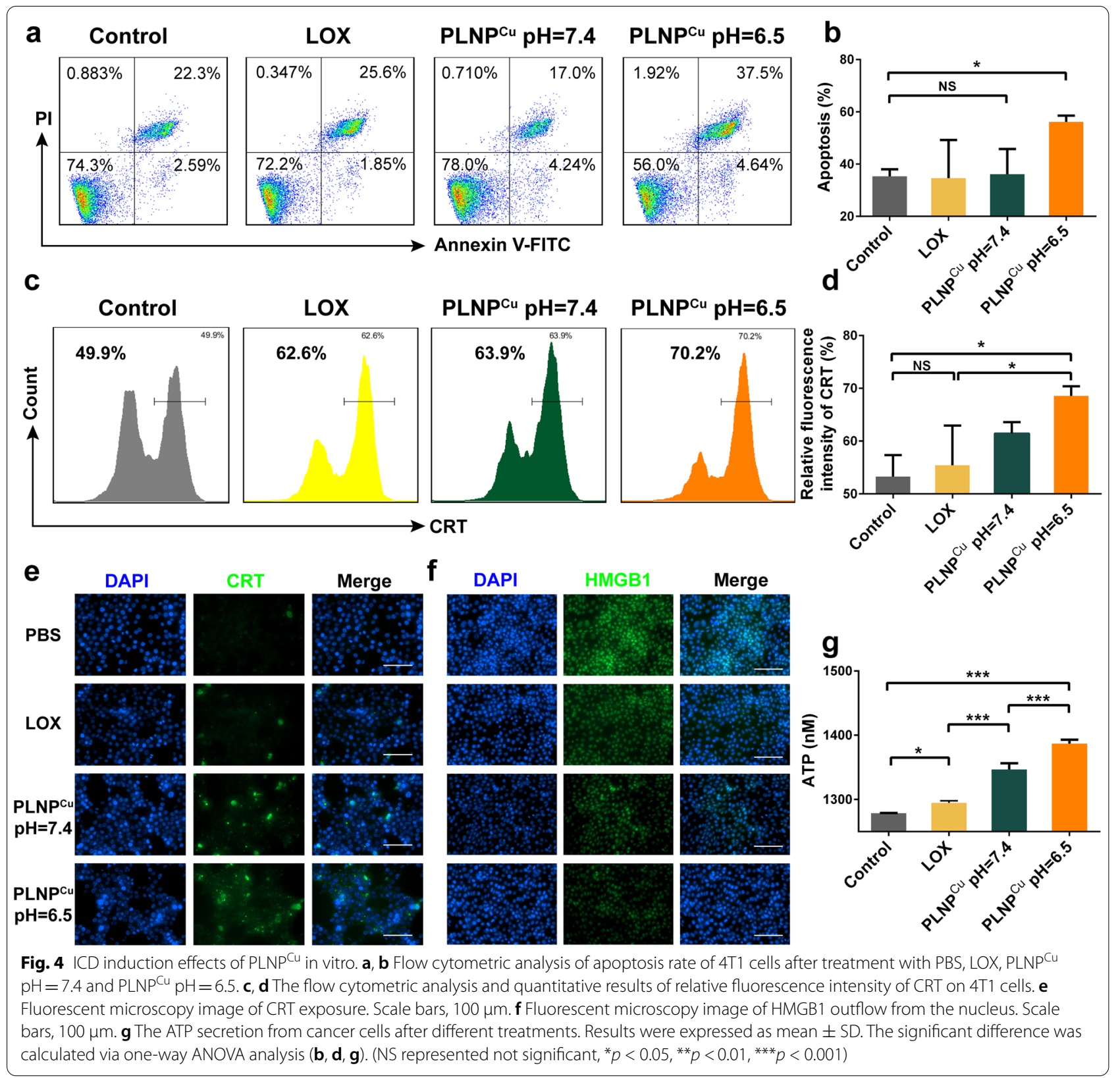

than the control group (Fig. 5a, c). Again, immunofluorescence images revealed that the $\mathrm{PLNP}^{\mathrm{Cu}}$ induced significant upregulation of the M1 biomarker CD80. (Green fluorescence signal of FITC labeled CD80, Fig. 5e). However, the RAW 264.7 macrophages displayed an insignificant change in M2-like polarization via analyzing the expression of CD206 (Fig. 5b, d), which may be due to the expression of CD206 both on M0 and M2-macrophage that compromises the alteration of M2 polarization [29]. Therefore, the M0-macrophage was induced by interleukin-4 (IL-4) for generation of the M2 phenotype and used for M2-macrophages in further studies. The results showed that PLNPCu upregulated expression of CD80 and, notedly, reduced CD206 expression on M2-macrophages (Fig. 5f, g). We also measured the expression of $\mathrm{M} 1$ and M2-associated genes via quantitative realtime polymerase chain reaction (qRT-PCR). The results revealed that $\mathrm{PLNP} \mathrm{Pu}^{\mathrm{Cu}}$ exposure significantly induced M1-related markers expression (CD80, TNF- $\alpha$ ) while M2-associated markers (CD206, Arg-1) were downregulated (Additional file 1: Fig. S14). Collectively, these results demonstrated that $\mathrm{PLNP}^{\mathrm{Cu}}$ induced macrophage 


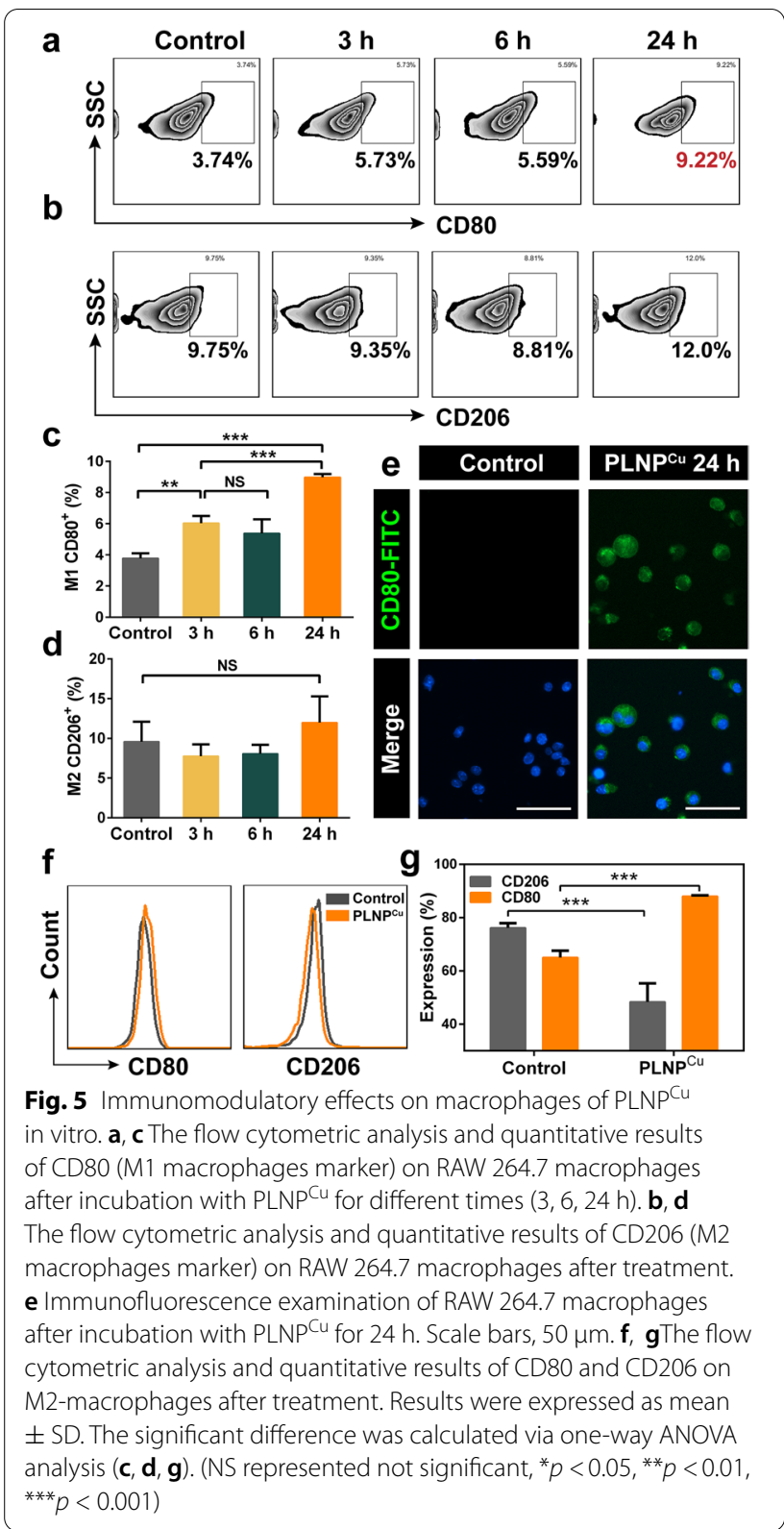

M1 polarization in vitro through the consumption of extracellular lactate, which potentiated the antitumoral immune response.

\section{Distribution and antitumor effects of PLNPCuin vivo}

PLNPCu@Cy7 was prepared to investigate the distribution of the PLNPCu in 4T1-bearing mice. The major organs (i.e., heart, liver, spleen, lung, and kidney) and tumors were collected within $1 \mathrm{~h}$ after tail vein injection of agents (Cy7-labeled LOX, PLNPCu$@ C y 7$ respectively) for ex vivo fluorescence imaging analysis. As shown in

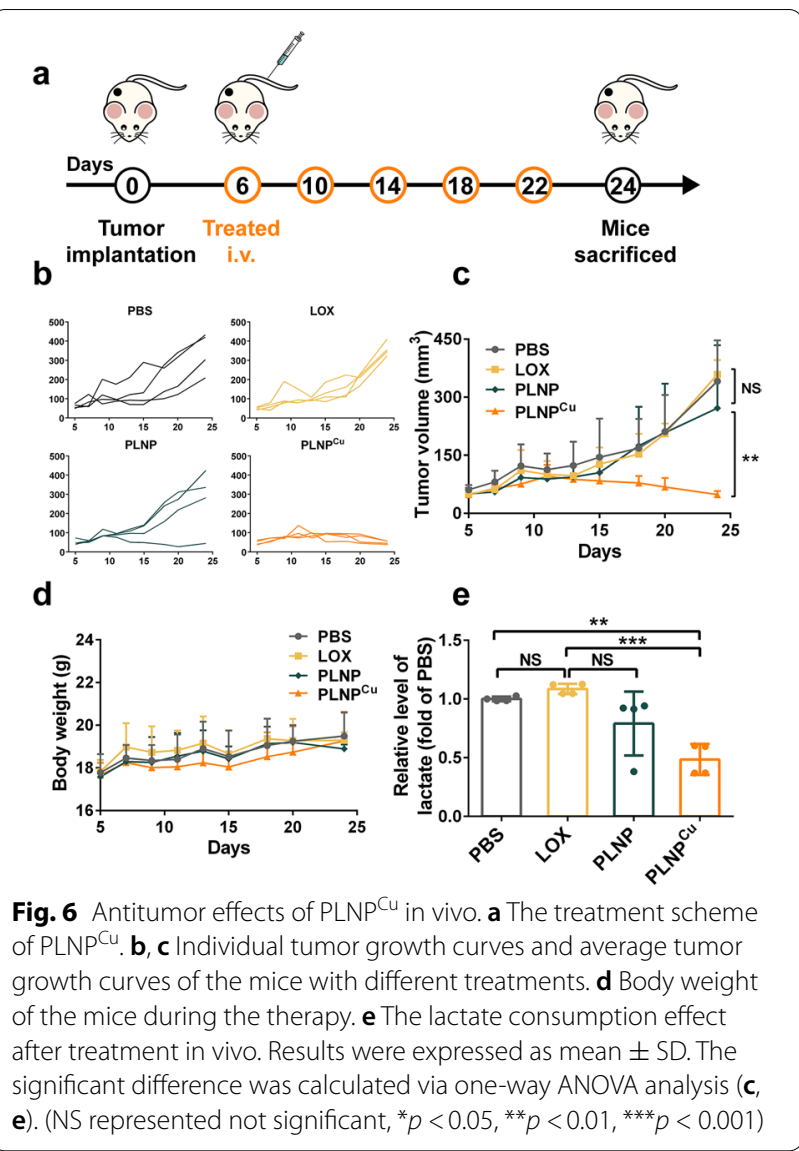

Additional file 1: Fig. S15, free LOX indicated a nonspecific distribution across the normal organs other than the tumor. In contrast, PLNP ${ }^{\mathrm{Cu}} @ \mathrm{Cy} 7$ were significantly enriched in tumor tissues, which might be attributed to the enhanced permeability and retention (EPR) effect [30]. And the enrichment of PLNP ${ }^{\mathrm{Cu}} @ \mathrm{Cy} 7$ in the liver was significantly lower than the free LOX, which decreased the immune-related adverse effects due to a non-specific enrichment of LOX in the liver. In conclusion, these findings suggested that $\mathrm{PLNP}^{\mathrm{Cu}}$ improved tumor targeting efficiency and accumulation, thereby decreasing the non-specific tissue distribution.

The antitumor effect and induction of systemic antitumor immune responses of PLNP ${ }^{\mathrm{Cu}}$ were investigated in the 4T1 tumor-bearing mouse model (a weakly immunogenic tumor) (Fig. 6a). After $18 \mathrm{~d}$ of administration (five i.v. injections totally), the $\mathrm{PLNP}^{\mathrm{Cu}}$ group exhibited the most effective tumor inhibition, while tumors showed similarly rapid growth in PBS and LOX groups (Fig. 6b, c). Specifically, PLNP ${ }^{\mathrm{Cu}}$ demonstrated $88 \%$ tumor inhibition, while the LOX only achieved 17\%, and PLNP showed a moderate inhibitory of $37 \%$ (Additional file 1: Fig. S16). The tumor volume indicated that PLNPCu effectively inhibited tumor growth in vivo. The same 


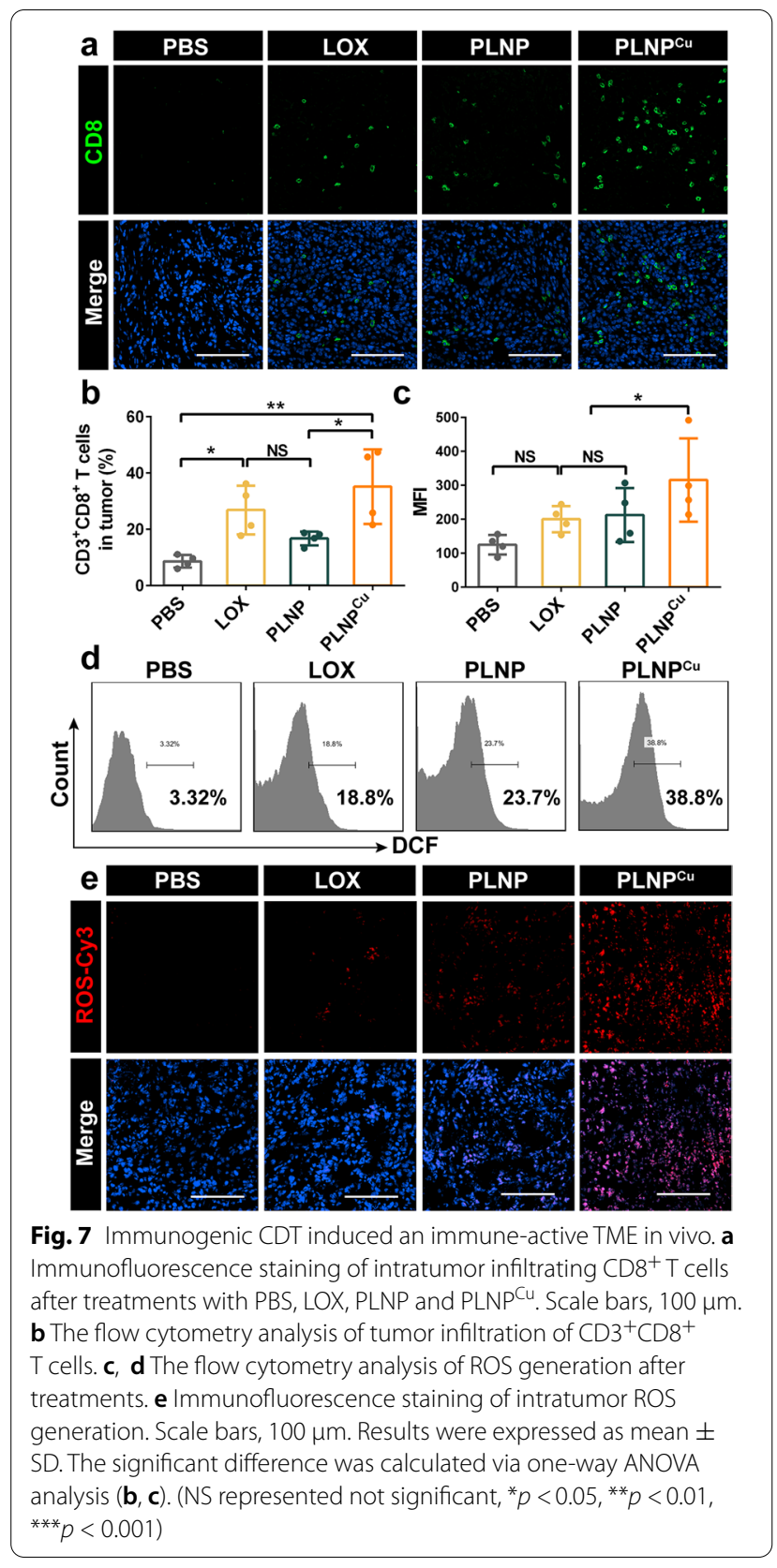

tendencies of body weight changes (Fig. 6d) and the no obvious tissue damage in $H \& E$ staining supported the safety of the PLNPCu treatment in vivo (Additional file 1 : Fig. S17).

The effects of the lactate treatment plant PLNPCu established in the tumor treatment were further discussed in more detail. Tumor tissues were collected and the intratumoral lactate content was detected after five treatments with PBS, LOX, PLNP, and PLNPCu. The PLNPCu showed the lowest relative level of lactate (the fold of PBS) in the tumor, at only 0.48 , which even reduced to half of the amount for the PBS or LOX group. The result of PLNP (0.79) indicated that thorough consumption and transition of intracellular lactate could counteract the active lactate metabolism in tumors, reflecting in the downregulation of intra/extracellular lactate levels (Fig. 6e). In general, PLNP ${ }^{\mathrm{Cu}}$ showed more effective lactate exhaustion than LOX or PLNP attributed to the effective tumor accumulation of nanoparticles and the well-functioning lactate treatment plant.

Although these experiments yielded good results, lactate consumption was only the first step of the lactate treatment plant. The generation of $\cdot \mathrm{OH}$ was quantified to validate the plant working properly. The generation of intracellular ROS in the tumor was detected by flow cytometry with the DCFH-DA probe. The MFI of the intracellular $\mathrm{ROS}$ in the $\mathrm{PLNP}^{\mathrm{Cu}}$ group was 3 times higher than that of the PBS. There was no significant difference between the LOX and PLNP groups and, markedly, both were lower than the PLNP ${ }^{\mathrm{Cu}}$ group (Fig. 7c, d). The above results confirmed that the PLNPCu triggered the massive generation of intracellular ROS in $4 \mathrm{~T} 1$ tumor cells. We estimated that the ROS was therefore mainly toxic $\cdot \mathrm{OH}$ that has a high affinity for DCFH-DA binding rather than $\mathrm{H}_{2} \mathrm{O}_{2}$ [31]. This conclusion was based on the minor amounts of ROS generation in PLNP group, specifically, the third step of the lactate treatment plant, i.e. Fenton-like reaction, was disrupted due to the absence of copper ion. Incidentally, the limited cell uptake and the insufficient toxic ROS generation of free LOX also demonstrated the positive role of the continuous-operated lactate treatment plant in tumor inhibition. The abundant bright red fluorescence was observed in confocal laser scanning microscope (CLSM) images of frozen tumor tissue sections, consistent with the flow cytometry results respectively (Fig. 7e). Together, the lactate treatment plant establishment triggered by $\mathrm{PLNP}^{\mathrm{Cu}}$ exhibited the most effective lactate exhaustion and tumor inhibition.

\section{Anti-tumor immune activation in vivo}

Encouraged by the well-functioning lactate treatment plant in tumor, we subsequently monitored its antitumor immune responses. For this purpose, the typical cell types of cellular immunity ( $\mathrm{T}$ cells) and innate immunity (macrophages, Tregs) were detected. The percentage of cytotoxic $\mathrm{T}$ lymphocytes (CTL, $\mathrm{CD}^{+} \mathrm{CD}^{+} \mathrm{T}$ cells) infiltration in tumors after $\mathrm{PLNP}^{\mathrm{Cu}}$ treatment was significantly increased compared with the PBS (4.06-fold higher) and PLNP (2.09-fold higher). There was a nonsignificant CTL proportion difference between LOX and PLNP groups. Although the slight upregulation of CTL was found in LOX (36.2\%), PLNP ${ }^{\mathrm{Cu}}$ showed the highest CTL proportion (1.30 times of LOX group) (Fig. $7 \mathrm{~b})$. The 


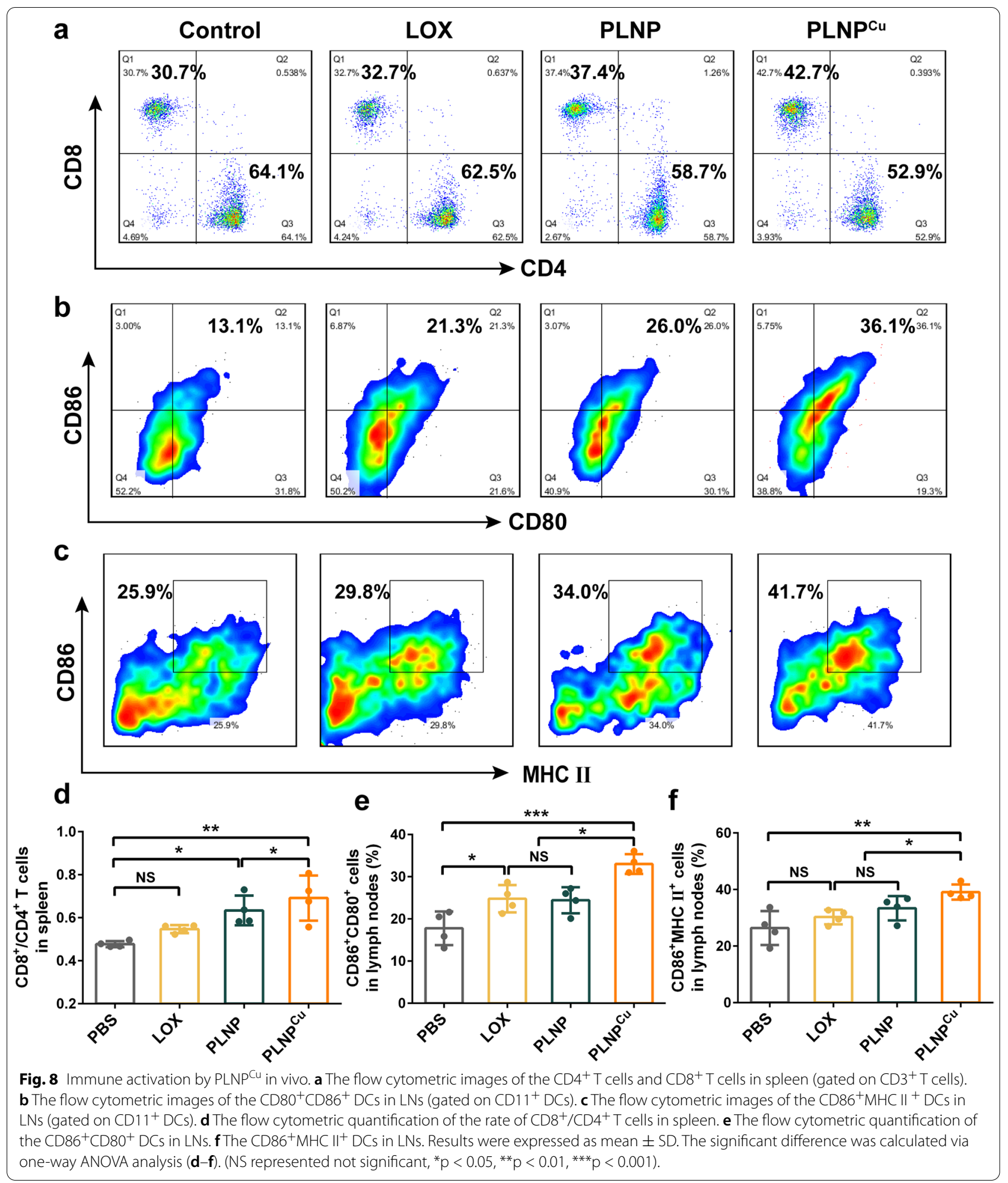

same results were observed in CLSM images, in which the copious green fluorescent signal at $488 \mathrm{~nm}$ confirmed higher $\mathrm{CD}^{+} \mathrm{T}$ cell infiltration in PLNP ${ }^{\mathrm{Cu}}$ group (Fig. 7a).
Furthermore, a typical cytokine (interferon- $\gamma$, IFN- $\gamma$ ) of immune activation in tumor tissues was detected. As expected, tumor tissues of PLNP ${ }^{\mathrm{Cu}}$ group presented the 
highest level of IFN- $\gamma$ after treatment (Additional file 1: Fig. S18). As it is well known, lactate production by cancer cells affects M2-like TAM polarization, which was associated with tumor growth, metastasis, and immunosuppression [3, 32]. According to tumor infiltration macrophages analysis, there was a significant increase in M1-like macrophages after PLNPCu treatment (Additional file 1: Fig. S19). In addition, regulatory $\mathrm{T}$ cells (Tregs) in TME inhibit effector $\mathrm{T}$ cells and the activation and proliferation of $\mathrm{CD}^{+} \mathrm{T}$ cell by consuming IL-2 and releasing perforin and granzyme [33, 34]. PLNPCu significantly lowered the number of tumor-infiltrating Tregs in immunofluorescence staining results (Additional file 1: Fig. S20). All the above results suggested that immune response activation at the tumor site was triggered through the establishment of the "lactate treatment plant" by PLNPCu.

The systemic anti-tumor immune response induced by $\mathrm{PLNP}^{\mathrm{Cu}}$ was also explored. The spleen, containing abundant immune cells, is the largest immune organ and the immune center of the body in supporting anti-tumor immune response activation [35]. We analyzed the phenotype and quantity of spleen $\mathrm{T}$ lymphocytes. As shown in the flow cytometry results, $\mathrm{CD} 8^{+} \mathrm{T}$ cells significantly increased in PLNPCu treatment group, the proportion of $\mathrm{CD}^{+}{ }^{+} \mathrm{T}$ cells was downregulated (Fig. 8a). Remarkably, $\mathrm{PLNP}^{\mathrm{Cu}}$ increased the rate of $\mathrm{CD}^{+} / \mathrm{CD} 4^{+} \mathrm{T}$ cells from 0.47 of PBS to 0.69 (Fig. 8d). Dendritic cells (DCs) present the tumor antigen to $\mathrm{T}$ cells, playing critical roles in pathogen sensing and initiation of anti-tumor immune responses. The DC maturation in draining lymph nodes (DLNs) including tumor DLNs was analyzed via flow cytometry. By qualitative and quantitative assays, the expressions of the DC maturation marker MHC II, CD86, and CD80 were up-regulated, confirming PLNPCu promotes DC maturation in DLNs (Fig. 8b, c, e and f). Together, all the immune analysis results suggesting that PLNP ${ }^{\mathrm{Cu}}$ activated the immune system for efficient inhibition of tumor cell growth.

\section{Conclusions}

In summary, a pH-responsive nanosystem PLNPCu was constructed with synergistic anti-tumor effects via the combinatorial treatment with both metabolic therapy and immunotherapy. PLNP ${ }^{\mathrm{Cu}}$ delicately used the tumor cell phsiology and TME to build the "lactate treatment plant", where the raw materials $\left(\mathrm{H}_{2} \mathrm{O}_{2}\right.$ that the enzymatic products of LOX, cuprous ions from nanosystem) processed into toxic $\cdot \mathrm{OH}$ products through Fenton-like reactions for ICD, and then the immune system was activated for tumor inhibition. Meanwhile, the intra/ extracellular lactate exhaustion remodeled the immunosuppressive TME, inducing TAM polarization to M1 phenotype and arousing the activity of immune cells around the tumor cells. Importantly, the $88 \%$ tumor inhibition was achieved with the PLNP ${ }^{\mathrm{Cu}}$ treatment alone without the introduction of additional agents.

\section{Supplementary Information}

The online version contains supplementary material available at https://doi. org/10.1186/s12951-021-01169-9.

Additional file 1. Supporting information including materials, methods, additional figures and tables.

Acknowledgements

Not applicable.

Authors' contributions

$\mathrm{RH}$ designed the research. $\mathrm{RH}$ and JZ developed methods, analyzed data, organized figures, wrote the manuscript, and performed most of the experiments. YL, SR, GC, DX, YUY, YSY, TZ and JG participated in the animal experiments. $\mathrm{RH}$ drew the scheme. $Y Z, X Z, H D$ and $Y L$ reviewed and revised the manuscript. All authors read and approved the final manuscript.

\section{Funding}

This work was financially supported through grants from the National Natural Science Foundation of China (51773154, 31771090), Shanghai Science and Technology Innovation (18JC1414500) and Young Hundred-Talent Program of Tongji University.

\section{Availability of data and materials}

All data generated or analyzed during this study are included in this published article and its Additional file 1.

\section{Declarations}

Ethics approval and consent to participate

All animal procedures in compliance with the guidelines of the Institutional Animal Care and Use Committee of Tongji University (TJAA07721102).

Consent for publication

All authors agreed to publish this manuscript.

Competing interests

The authors declare no conflict of interest.

Received: 1 October 2021 Accepted: 28 November 2021

Published online: 18 December 2021

References

1. Mbeunkui F, Johann DJ. Cancer and the tumor microenvironment: a review of an essential relationship. Cancer Chemotherapy Pharmacol. 2009;63:571-82.

2. Doherty JR, Cleveland JL. Targeting lactate metabolism for cancer therapeutics. J Clin Invest. 2013;123:3685-92.

3. Certo M, Tsai CH, Pucino V, Ho PC, Mauro C. Lactate modulation of immune responses in inflammatory versus tumour microenvironments. Nat Rev Immunol. 2020;21:151-61.

4. Romero-Garcia S, Moreno-Altamirano MMB, Prado-Garcia H, Javier Sanchez-Garcia F. Lactate contribution to the tumor microenvironment: mechanisms, effects on immune cells and therapeutic relevance. Front Immunol. 2016;7:52.

5. Hirschhaeuser F, Sattler UGA, Mueller-Klieser W. Lactate: a metabolic key player in cancer. Cancer Res. 2011;71:6921-5. 
6. Kolb D, Kolishetti N, Surnar B, Sarkar S, Guin S, Shah AS, Dhar S. Metabolic modulation of the tumor microenvironment leads to multiple checkpoint inhibition and immune cell infiltration. ACS Nano. 2020;14:11055-66.

7. Li K, Lin C, He Y, Lu L, Xu K, Tao B, Xia Z, Zeng R, Mao Y, Luo Z, Cai K. Engineering of cascade-responsive nanoplatform to inhibit lactate efflux for enhanced tumor chemo-immunotherapy. ACS Nano. 2020;14:14164-80.

8. Tang J, Meka AK, Theivendran S, Wang Y, Yang Y, Song H, Fu J, Ban W, Gu Z, Lei C, et al. Openwork@dendritic mesoporous silica nanoparticles for lactate depletion and tumor microenvironment regulation. Angewandte Chemie Int Edition English. 2020;59:22054-62.

9. Gao F, Tang Y, Liu WL, Zou MZ, Huang C, Liu CJ, Zhang XZ. Intra/extracellular lactic acid exhaustion for synergistic metabolic therapy and immunotherapy of tumors. Adv Mater. 2019;31:e1904639.

10. Zhou X, Zhao W, Wang M, Zhang S, Li Y, Hu W, Ren L, Luo S, Chen Z. Dualmodal therapeutic role of the lactate oxidase-embedded hierarchical porous zeolitic imidazolate framework as a nanocatalyst for effective tumor suppression. Acs Appl Mater Interfaces. 2020;12:32278-88.

11. Wang H, Cheng L, Ma S, Ding L, Zhang W, Xu Z, Li D, Gao L. Self-assembled multiple-enzyme composites for enhanced synergistic cancer starving-catalytic therapy. Acs Appl Mater Interfaces. 2020;12:20191-201.

12. Tseng SJ, Kempson IM, Huang KY, Li HJ, Fa YC, Ho YC, Liao ZX, Yang PC. Targeting tumor microenvironment by bioreduction-activated nanoparticles for light-triggered virotherapy. Acs Nano. 2018;12:9894-902.

13. Reyes-De-Corcuera JI, Olstad HE, Garcia-Torres R. Stability and stabilization of enzyme biosensors: the key to successful application and commercialization. Annu Rev Food Sci Technol. 2018;9:293-322.

14. Mei X, Hu TT, Wang H, Liang RZ, Bu WB, Wei M. Highly dispersed nanoenzyme triggered intracellular catalytic reaction toward cancer specific therapy. Biomaterials. 2020;258:150257.

15. Huang Z, Yao D, Ye Q, Jiang H, Gu R, Ji C, Wu J, Hu Y, Yuan A. Zoledronic acid-gadolinium coordination polymer nanorods for improved tumor radioimmunotherapy by synergetically inducing immunogenic cell death and reprogramming the immunosuppressive microenvironment. ACS Nano. 2021;15:8450-65.

16. Zhao HY, Wang YJ, Wang YB, Cao TC, Zhao GH. Electro-Fenton oxidation of pesticides with a novel Fe3O4@Fe2O3/activated carbon aerogel cathode: high activity, wide $\mathrm{pH}$ range and catalytic mechanism. Appl Catalysis B-Environ. 2012:125:120-7.

17. Brillas E, Banos MA, Camps S, Arias C, Cabot PL, Garrido JA, Rodriguez RM. Catalytic effect of Fe2+, Cu2 + and UVA light on the electrochemical degradation of nitrobenzene using an oxygen-diffusion cathode. New J Chem. 2004:28:314-22.

18. Cao R, Sun W, Zhang Z, Li XJ, Du JJ, Fan JL, Peng XJ. Protein nanoparticles containing $\mathrm{Cu}(\mathrm{II})$ and DOX for efficient chemodynamic therapy via selfgeneration of $\mathrm{H}_{2} \mathrm{O}_{2}$. Chin Chem Lett. 2020;31:3127-30.

19. Lian Z, Ji TJ. Functional peptide-based drug delivery systems. J Mater Chem B. 2020;8:6517-29.

20. Wu GY, Fang YZ, Yang S, Lupton JR, Turner ND. Glutathione metabolism and its implications for health. J Nutr. 2004;134:489-92.

21. Bansal A, Simon MC. Glutathione metabolism in cancer progression and treatment resistance. J Cell Biol. 2018:217:2291-8.

22. Ma B, Wang S, Liu F, Zhang S, Duan J, Li Z, Kong Y, Sang Y, Liu H, Bu W, Li L. Self-assembled copper-amino acid nanoparticles for in situ glutathione "AND" $\mathrm{H} 2 \mathrm{O} 2$ sequentially triggered chemodynamic therapy. J Am Chem Soc. 2019;141:849-57.

23. Wu HS, Chen FH, Gu DH, You CQ, Sun BW. A pH-activated autocatalytic nanoreactor for self-boosting Fenton-like chemodynamic therapy. Nanoscale. 2020;12:17319-31.

24. Chen F, Chen JN, Yang LB, Liu J, Zhang XQ, Zhang Y, Tu QQ, Yin D, Lin DC, Wong PP, et al. Extracellular vesicle-packaged HIF-1 alpha-stabilizing IncRNA from tumour-associated macrophages regulates aerobic glycolysis of breast cancer cells. Nat Cell Biol. 2019;21:498-510.

25. Ma PA, Xiao HH, Yu C, Liu JH, Cheng ZY, Song HQ, Zhang XY, Li CX, Wang JQ, Gu Z, Lin J. Enhanced cisplatin chemotherapy by iron oxide nanocarrier-mediated generation of highly toxic reactive oxygen species. Nano Lett. 2017:17:928-37.

26. Galluzzi L, Buque A, Kepp O, Zitvogel L, Kroemer G. Immunogenic cell death in cancer and infectious disease. Nat Rev Immunol. 2017;17:97-111.

27. Kondratova M, Czerwinska U, Sompairac N, Amigorena SD, Soumelis V, Barillot E, Zinovyev A, Kuperstein I. A multiscale signalling network map of innate immune response in cancer reveals cell heterogeneity signatures. Nat Commun. 2019;10:1.

28. Lovisa S, LeBleu VS, Tampe B, Sugimoto H, Vadnagara K, Carstens JL, Wu CC, Hagos Y, Burckhardt BC, Pentcheva-Hoang T, et al. Epithelial-to-mesenchymal transition induces cell cycle arrest and parenchymal damage in renal fibrosis. Nat Med. 2015;21:998-1009.

29. Liao ZX, Fa YC, Kempson IM, Tseng SJ. Repolarization of M2 to M1 macrophages triggered by lactate oxidase released from methylcellulose hydrogel. Bioconjug Chem. 2019;30:2697-702.

30. Ji TJ, Kohane DS. Nanoscale systems for local drug delivery. Nano Today. 2019;28:100765.

31. Zhang L, Wan SS, Li CX, Xu L, Cheng H, Zhang XZ. An adenosine triphosphate-responsive autocatalytic fenton nanoparticle for tumor ablation with self-supplied $\mathrm{H}_{2} \mathrm{O}_{2}$ and acceleration of $\mathrm{Fe}(\mathrm{III}) / \mathrm{Fe}(\mathrm{II})$ conversion. Nano Lett. 2018;18:7609-18.

32. Tsai CS, Chen FH, Wang CC, Huang HL, Jung SM, Wu CJ, Lee CC, McBride WH, Chiang CS, Hong JH. Macrophages from irradiated tumors express higher levels of iNOS, Arginase-l and COX-2, and promote tumor growth. Int J Radiat Oncol Biol Phys. 2007;68:499-507.

33. Li LY, Miao QW, Meng FQ, Li BQ, Xue TY, Fang TL, Zhang ZR, Zhang JX, Ye $X Y$, Kang $Y$, et al. Genetic engineering cellular vesicles expressing CD64 as checkpoint antibody carrier for cancer immunotherapy. Theranostics. 2021;11:6033-43.

34. Zhang XD, Wang C, Wang JQ, Hu QY, Langworthy B, Ye YQ, Sun WJ, Lin J, Wang TF, Fine J, et al. PD-1 blockade cellular vesicles for cancer immunotherapy. Adv Mater. 2018;30:1707112.

35. Yang J, Wang B, Zhang CF, Xu XH, Zhang M. A C-21-steroidal glycoside from Cynanchum atratum attenuates concanavalin A-induced liver injury in mice. Molecules. 2019;24:1087.

\section{Publisher's Note}

Springer Nature remains neutral with regard to jurisdictional claims in published maps and institutional affiliations.

Ready to submit your research? Choose BMC and benefit from

- fast, convenient online submission

- thorough peer review by experienced researchers in your field

- rapid publication on acceptance

- support for research data, including large and complex data types

- gold Open Access which fosters wider collaboration and increased citations

- maximum visibility for your research: over $100 \mathrm{M}$ website views per year

At BMC, research is always in progress.

Learn more biomedcentral.com/submissions 